\title{
Prognostic implication of mucinous histology in colorectal cancer patients treated with adjuvant FOLFOX chemotherapy
}

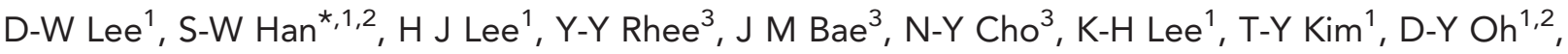 \\ S-A Im ${ }^{1,2}$, Y-J Bang ${ }^{1,2}$, S-Y Jeong ${ }^{4}, \mathrm{~K} \mathrm{~J} \mathrm{Park}^{4}, \mathrm{~J}_{-\mathrm{G}}$ Park $^{4}, \mathrm{G} \mathrm{H} \mathrm{Kang}{ }^{3}$ and T-Y Kim ${ }^{1,2,5}$
}

${ }^{1}$ Department of Internal Medicine, Seoul National University Hospital, Seoul, Korea; ${ }^{2}$ Cancer Research Institute, Seoul National University College of Medicine, Seoul, Korea; ${ }^{3}$ Department of Pathology, Seoul National University College of Medicine, Seoul, Korea; ${ }^{4}$ Department of Surgery, Seoul National University Hospital, Seoul, Korea and ${ }^{5}$ Department of Molecular Medicine and Biopharmaceutical Sciences, Graduate School of Convergence Science and Technology, Seoul National University, Seoul, Korea

Background: There have been controversies in prognostic impact of mucinous histology on colorectal cancer, and its implication in patients treated with adjuvant 5-fluorouracil, leucovorin, and oxaliplatin (FOLFOX) is unclear.

Methods: Stage II and III colorectal cancer patients who underwent curative resection followed by adjuvant FOLFOX were included. Patients were grouped according to the mucinous content: $>50 \%$, mucinous adenocarcinoma (MAC); $<50 \%$, adenocarcinoma with intermediated mucinous component (AIM); and without any mucinous component, non-MAC (NMA). Clinicopathological features and disease-free survival (DFS) were compared.

Results: Among a total of 521 patients, 27 patients (5.2\%) had MAC, 41 patients (7.9\%) had AIM, and 453 patients (86.9\%) had NMA. Mucinous adenocarcinoma and AIM had higher frequency of proximal location and microsatellite instability, but lower frequency of angiolymphatic invasion. Disease-free survival was significantly worse in the MAC compared with NMA (3-year DFS $57 \%$ and $86 \%$, respectively; $P<0.001$ ) and AIM (3-year DFS 87\%, $P=0.01$ vs MAC). Multivariate analysis revealed MAC as an independent negative prognostic factor of DFS (adjusted hazard ratio 7.96, 95\% confidence interval 3.76-16.8).

Conclusion: Adenocarcinoma with intermediated mucinous component and MAC have distinct clinicopathological features compared with NMA. Mucinous adenocarcinoma has an adverse prognostic impact on stage II or III colorectal cancer treated with adjuvant FOLFOX.

Colorectal mucinous adenocarcinoma (MAC) is a subtype of colorectal adenocarcinoma with prominent mucin (MUC) production. In the World Health Organisation (WHO) classification, MAC is defined as an adenocarcinoma in which $>50 \%$ of the lesion is composed of pools of extracellular mucin (Bosman, 2010). Tumour with $<50 \%$ of the lesion composed of mucin is categorised as having mucinous component. Mucinous adenocarcinoma is associated with proximal location of tumour, advanced stage at diagnosis, microsatellite instability (MSI), and BRAF mutation compared with non-MAC (Green et al, 1993; Younes et al, 1993; Kakar et al, 2004; Song et al, 2005; Leopoldo et al,
2008). The frequency of MAC among colorectal cancer varies according to geographic origin, Western studies exhibiting higher frequencies compared with Asian studies, suggesting possible ethnic difference in pathogenesis (Wu et al, 1996; Kanemitsu et al, 2003; Du et al, 2004; Papadopoulos et al, 2004; Kang et al, 2005; Lee et al, 2007; Leopoldo et al, 2008; Xie et al, 2009). Previous studies have reported poor response and survival following palliative chemotherapy in advanced colorectal cancer with mucinous histology (Negri et al, 2005; Catalano et al, 2009). Moreover, a recent meta-analysis showed $2-8 \%$ increased hazard of death associated with mucinous histology (Verhulst et al, 2012).

*Correspondence: Professor S-W Han; E-mail: saewon1@snu.ac.kr

Received 22 January 2013; revised 16 March 2013; accepted 15 April 2013; published online 7 May 2013

(c) 2013 Cancer Research UK. All rights reserved 0007-0920/13 
However, other studies have failed to demonstrate the adverse prognostic impact of mucinous histology on treatment outcome (Farhat et al, 2008; Catalano et al, 2012; Langner et al, 2012). Different outcomes of MAC according to MSI status have been reported exhibiting better outcome with MSI compared with microsatellite stable (MSS) among MAC (Kakar et al, 2004; Leopoldo et al, 2008).

Adjuvant chemotherapy using 5-fluorouracil, leucovorin, and oxaliplatin (FOLFOX) is commonly used in stage III colon cancer, as it can reduce recurrence and mortality in these patients (Andre et al, 2009). However, the exact prognostic impact of mucinous histology on colorectal cancer patients treated with adjuvant FOLFOX is unclear. This study aimed at elucidating the prognostic implication of MAC among colorectal cancer in the current era of adjuvant FOLFOX. Furthermore, we investigated clinicopathological features and prognostic effect of mucinous component of $<50 \%$, of which only limited data have been reported.

\section{MATERIALS AND METHODS}

Patients and treatment. We retrospectively analysed patients with stage II or III colorectal cancer treated with adjuvant FOLFOX chemotherapy between April 2005 and December 2011. Patients were eligible if they met the following criteria: age over 18, adenocarcinoma histology, stage III or high-risk stage II, complete resection of the tumour with negative margin, and completion of at least six cycle of adjuvant FOLFOX chemotherapy. High-risk stage II was defined if they had any of the following: T4 lesion, obstruction or perforation, lymphovascular invasion, perineural invasion, or poorly differentiated histology. Patients with upper rectal cancer were included if the patient did not receive pre- or post-operative radiation. Exclusion criteria were the following: previous chemotherapy for CRC, previous radiotherapy for CRC, signet ring cell histology, distant metastasis, and history of other malignancy within 5 years. All patients received surgery and chemotherapy at Seoul National University Hospital, and eligible patients were identified from the electronic medical record of Seoul National University Hospital. The study protocol was reviewed and approved by the institutional review board of Seoul National University Hospital.

Patient received FOLFOX chemotherapy as either FOLFOX-4 or modified FOLFOX-6 regimen. Patients who started chemotherapy before July 2009 received FOLFOX-4 and after July 2009 received modified FOLFOX-6. Each cycle of FOLFOX-4 consisted of oxaliplatin $\left(85 \mathrm{mg} \mathrm{m}^{-2}\right)$ on day 1 , folinic acid $\left(200 \mathrm{mg} \mathrm{m}^{-2}\right)$, and a bolus of 5-fluorouracil (FU) $\left(400 \mathrm{mg} \mathrm{m}^{-2}\right.$ ) followed by a 22 $\mathrm{h}$ infusion of 5 -FU $\left(600 \mathrm{mg} \mathrm{m}^{-2}\right)$ on days 1 and 2, which was repeated every 2 weeks. Modified FOLFOX-6 consisted of oxaliplatin $\left(85 \mathrm{mg} \mathrm{m}^{-2}\right)$, folinic acid $\left(400 \mathrm{mg} \mathrm{m}^{-2}\right)$, and a bolus of 5 -FU $\left(400 \mathrm{mg} \mathrm{m}^{-2}\right)$ followed by a $46-\mathrm{h}$ infusion of $5-\mathrm{FU}$ $\left(2400 \mathrm{mg} \mathrm{m}^{-2}\right)$ repeated every 2 weeks. Adjuvant chemotherapy was planned for a total of 12 cycles.

Patients were assessed every 2 weeks during chemotherapy treatment, and then at least every 6 months for 5 years. The postchemotherapy period assessment included a medical history taking, physical examination, measurement of the carcinoembryonic antigen level, chest computed tomography, and abdominal computed tomography. The diagnosis of recurrence was made on the basis of imaging and, if necessary, biopsy.

Pathological examination. Mucinous adenocarcinoma was defined according to the WHO classification, which is $>50 \%$ of the tumour lesion composed of pools of extracellular MUC (Bosman, 2010). In the present study, we defined tumours with mucinous area of $<50 \%$ as adenocarcinoma with intermediate mucinous component (AIM) in order to avoid confusion with
MAC. Non-MAC (NMA) was defined as cancer without any mucinous component.

The microsatellite status of each tumour was determined by evaluating five microsatellite markers (D2S123, D5S346, D17S250, BAT25, and BAT26). Either forward or reverse primer for each marker was labelled with fluorescence, and PCR products were electrophoresed and analysed. We classified MSI status as follows: high MSI (MSI-H; instability at $\geqslant 2$ microsatellite markers), low MSI (MSI-L; instability at 1 marker), or MSS (no instability). Only MSI-H was regarded as having MSI, and MSI-L was grouped with MSS.

Statistical analysis. The objective of this study was to investigate the effect of mucinous histology (MAC and AIM) on the treatment outcome (disease-free survival (DFS)) of colorectal cancer patients treated with adjuvant FOLFOX chemotherapy. Disease-free survival was calculated from the date of operation to the first date of documented progressive disease or the date of death from any cause. Data from patients who were free of progression were censored at the date of the last follow-up visit for DFS. Categorical variables were compared using $\chi^{2}$-test or Fisher's exact test as appropriate. Disease-free survival was calculated using the KaplanMeier method, and comparisons were made using the log-rank tests. Hazard ratios (HRs) were calculated using the Cox proportional hazard model. To adjust for the baseline characteristics, Cox proportional hazard analysis of DFS included age, sex, $\mathrm{T}$ stage, $\mathrm{N}$ stage, tumour location, angiolymphatic invasion, venous invasion, perineural invasion, and MSI status. Two-sided $P$-values of $<0.05$ were considered statistically significant. Statistical analysis was performed with SPSS software for Windows, version 17.0 (SPSS, Chicago, IL, USA).

\section{RESULTS}

Patient characteristics. A total of 521 patients with stage II or III colorectal cancer, treated with adjuvant FOLFOX chemotherapy, were included. Baseline characteristics are summarised in Table 1. Tumour location was caecum in 24 , ascending colon in 118 , transverse in 39 , descending in 33 , sigmoid in 275 , and rectum in 32 patients. Collectively, 181 patients had tumour in proximal (from caecum to transverse colon) location and 340 patients had tumour in distal location. Tumour stage was stage II in 78 patients (IIA in 53, IIB in 21 , and IIC in 4 ) and stage III in 443 patients (IIIA in 39 , IIIB in 289, and IIIC in 115). All stage II patients had high-risk features. Microsatellite instability (MSI-H) was shown in $6.8 \%$ of tumours. MSI was more frequently observed in proximal location ( $13.9 \%$ vs $3.0 \%$ in distal location, $P<0.001)$. There was no significant difference in MSI incidence according to tumour stage, sex, or age. According to the inclusion criteria, all patients received at least 6 cycles of chemotherapy, and $88.8 \%$ of patients completed planned 12 cycles of chemotherapy.

Clinicopathological characteristics of mucinous histology. Twenty-seven patients (5.2\%) had MAC and 41 patients (7.9\%) had AIM. The remaining 453 patients (86.9\%) had NMA. Tumours with mucinous component (AIM and MAC) were more frequently found in proximal location (61.0\% in AIM and 59.3\% in MAC vs $30.9 \%$ in NMA), less likely to show angiolymphatic invasion (29.3\% in AIM and $22.2 \%$ in MAC vs $45.3 \%$ in NMA), and more likely to have microsatellite instability (14.6\% in AIM and $14.8 \%$ in MAC vs 5.6\% in NMA) compared with NMA (Table 1). Venous invasion and perineural invasion tended to be also less frequently observed in AIM and MAC.

Although AIM and MAC showed similar clinicopathological features described above, differences were also found. Adenocarcinoma with intermediated mucinous component was more frequently observed in patients over 65 years old $(46.3 \%$ in AIM 
Table 1. Patient characteristics and mucinous histology

$\boldsymbol{P}$-values

\begin{tabular}{|l|l|l|l|l|l|l} 
Total $(N=521)$ & NMA $(N=453)$ & AIM $(N=41)$ & MAC $(N=27)$ & AIM vs NMA & MAC vs NMA & AIM vs MAC
\end{tabular}

\section{Age}

\section{Median (range)}

$\geqslant 65$ years

\section{Sex}

Male

Female

Location

Proximal

Distal

Stage

II

III

T stage

T1-3

$\mathrm{T} 4$

N stage

NO-1

N2

$60(25-81)$
$155(29.8 \%)$

60 (35-76)

$128(28.3 \%)$

$62(25-81)$
$19(46.3 \%)$

283 (62.5\%)

170 (37.5\%)

312 (59.9\%)

209 (40.1\%)

$56(30-81)$
$8(29.6 \%)$

0.015

0.88

0.17

$<0.001$

$16(59.3 \%)$
$11(40.7 \%)$

$11(40.7 \%)$

\begin{tabular}{|l|l|l}
\hline$<0.001$ & 0.74 & 0.025 \\
\hline
\end{tabular}

181 (34.7\%)

140 (30.9\%)

\begin{tabular}{l|l}
\hline $25(61.0 \%)$ & $16(59.3 \%)$ \\
$16(39.0 \%)$ & $11(40.7 \%)$
\end{tabular}

$<0.001$

\begin{tabular}{|l|l|}
\hline 0.002 & 0.89 \\
\hline
\end{tabular}

$313(69.1 \%)$

$16(39.0 \%)$

\begin{tabular}{c|c}
$67(14.8 \%)$ & $7(17.1 \%)$ \\
$386(85.2 \%)$ & $34(82.9 \%)$
\end{tabular}

$78(15.0 \%)$
$443(85.0 \%)$

$386(85.2 \%)$

$34(82.9 \%)$

$4(14.8 \%)$
$23(85.2 \%)$

\begin{tabular}{|l|l|l|}
\hline 0.70 & 1.0 & 1.0 \\
\hline
\end{tabular}

$445(85.4 \%)$
$76(14.6 \%)$

$394(87.0 \%)$
$59(13.0 \%)$

\begin{tabular}{|c|c|}
\hline $35(85.4 \%)$ & $16(59.3 \%)$ \\
$6(14.6 \%)$ & $11(40.7 \%)$ \\
\hline
\end{tabular}

0.77

\begin{tabular}{l|l|l}
\hline 0.77 & $<0.001$ & 0.015 \\
\hline
\end{tabular}

$378(72.6 \%)$
$143(27.4 \%)$

$332(73.3 \%)$
$121(26.7 \%)$

$29(70.7 \%)$
$12(29.3 \%)$

$17(63.0 \%)$

\section{Angiolymphatic invasion}

\begin{tabular}{|l|}
\hline $\begin{array}{l}\text { Present } \\
\text { Absent }\end{array}$ \\
\hline Venous invasion \\
\hline Present
\end{tabular}

\begin{tabular}{|l|l|}
$223(42.8 \%)$ & \\
$298(57.2 \%)$ & \\
\hline
\end{tabular}

\begin{tabular}{|l|l|r|}
\hline $205(45.3 \%)$ & $12(29.3 \%)$ & $6(22.2 \%)$ \\
$248(54.7 \%)$ & $29(70.7 \%)$ & $21(77.8 \%)$ \\
\hline
\end{tabular}

\begin{tabular}{|c|c|c|}
\hline 0.72 & 0.24 & 0.50 \\
\hline
\end{tabular}

\begin{tabular}{|l|l|}
\hline $\begin{array}{l}\text { Present } \\
\text { Absent }\end{array}$ & \\
\hline Perineural invasion \\
\hline Present
\end{tabular}

\begin{tabular}{|l|l|}
\hline $\begin{array}{l}\text { Present } \\
\text { Absent }\end{array}$ & \\
\hline Microsatellite status \\
\hline MSS + MSI-L
\end{tabular}

$57(10.9 \%)$
$464(89.1 \%)$

$54(11.9 \%)$
$399(88.1 \%)$

\begin{tabular}{c|}
$1(2.4 \%)$ \\
$40(97.6 \%)$
\end{tabular}

$2(7.4 \%)$
$25(92.6 \%)$

0.048

\begin{tabular}{l|l|l|}
\hline & 0.019 & 0.52 \\
\hline & 0.76 & 0.56 \\
\hline
\end{tabular}

0.070

MSI-

$120(23.0 \%)$

$401(77.0 \%)$

\begin{tabular}{|c|c|}
\hline $112(24.7 \%)$ & $5(12.2 \%)$ \\
$341(75.3 \%)$ & $36(87.8 \%)$
\end{tabular}

$3(11.1 \%)$

$24(88.9 \%)$

\begin{tabular}{|l|l|}
\hline & 0.084 \\
\end{tabular}

0.16

\begin{tabular}{|l|l}
\hline .16 & 1.00 \\
\hline & \\
\hline & \\
\hline
\end{tabular}

\begin{tabular}{|c|c|c|c|}
\hline $483(93.2 \%)$ & $425(94.4 \%)$ & $35(85.4 \%)$ & $23(85.2 \%)$ \\
$35(6.8 \%)$ & $25(5.6 \%)$ & $6(14.6 \%)$ & $4(14.8 \%)$ \\
\hline
\end{tabular}

Abbreviations: $\mathrm{AIM}=$ adenocarcinoma with intermediate mucinous component; $\mathrm{MAC}=$ mucinous adenocarcinoma; $\mathrm{MSI}-\mathrm{H}=$ high microsatellite instability; $\mathrm{MSI}-\mathrm{L}=$ low microsatellite instability; MSS = microsatellite stable; NMA = non-mucinous adenocarcinoma.

vs $29.6 \%$ in MAC and $28.3 \%$ in NMA) and in female $(68.3 \%$ in AIM $v s 40.7 \%$ in MAC and $37.5 \%$ in NMA) patients compared with MAC and NMA. In contrast, higher proportion of MAC had T4 tumour (40.7\% in MAC vs $14.6 \%$ in AIM and $13.0 \%$ in NMA) compared with AIM and NMA.

Prognostic implication of mucinous histology. After a median follow-up duration of 38 months, 72 recurrent events (62 distant metastases and 10 local recurrences) have occurred. The 3-year DFS of the entire cohort was $84.9 \%$.

Disease-free survival was significantly worse in the MAC compared with NMA (3-year DFS 57\% and 86\%, respectively; $P<0.001$ ) (Figure 1). Interestingly, DFS of AIM (3-year DFS 87\%) was similar to NMA $(P=0.40)$ and significantly better than MAC $(P=0.01)$.

At the time of analysis, 10 patients in the MAC group, 4 patients in AIM group, and 58 patients in the NMA group had recurrence. There was no difference in pattern of recurrence (local recurrence vs distant metastasis) between each group (Table 2). Regarding initial sites of distant metastasis, AIM and MAC had higher percentage of peritoneal seeding compared with NMA, whereas lymph node was not involved in MAC. However, we could not make meaningful comparisons as only limited number of recurrent cases, especially for MAC and AIM, are involved in the present analysis. Among the patients with recurrence, we had tissue specimen from metastatic site in seven patients with MAC and two patients with AIM. Review of the pathological specimen from the 
metastatic site in patients with initial MAC showed that four patients had MAC, two patients had AIM, and one patient had NMA in the metastasis. In cases of initial AIM, one patient had AIM, whereas the other patient had NMA in the metastasis. Collectively, 78\% (7 out of 9) of patients with initial tumour with mucinous component (MAC and AIM) retained MUC production in the recurrent metastatic tumour.

In addition to MAC histology, following clinicopathological features were associated with poor treatment outcome: T4 stage, N2 stage, angiolymphatic invasion, venous invasion, and perineural invasion (Table 3). Other factors including MSI were not significantly associated with DFS. Although MSI-H showed trend towards favourable 3-year DFS compared with MSS/MSI-L $(90.0 \%$ vs $84.1 \%)$, there was no statistically significant difference $(P=0.46)$. There was no significant DFS difference according to MSI in any subgroup of patients (tumour location, stage, or sex). We could not compare the DFS according to MSI because only limited number of patients showed MSI among MAC (four patients) and AIM (six patients).

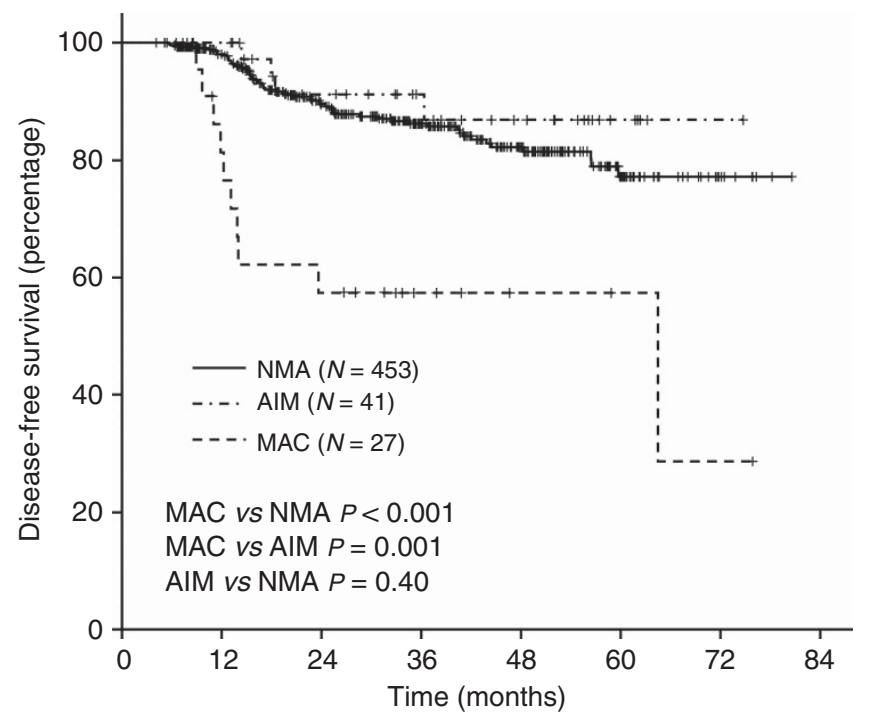

Figure 1. Kaplan-Meier curves of DFS according to mucinous histology.
To examine whether MAC was independently associated with poor DFS, we used the Cox proportional hazard model in a forward stepwise manner with variables in Table 3 as covariates. Multivariate analysis revealed that MAC was an independent negative prognostic factor (Table 4). Mucinous adenocarcinoma had significantly higher risk of recurrence (adjusted HR 7.96) compared with non-MAC (NMA and AIM). We also conducted multivariate analysis using combined stage (i.e., IIa, IIb, IIc, IIIa, IIIb, and IIIc) instead of individual $\mathrm{T}$ stage and $\mathrm{N}$ stage as covariates. Similar result was obtained showing $\mathrm{MAC}$ as an independent negative prognostic factor (adjusted HR 7.42; $P<0.001$ ).

\section{DISCUSSION}

The aim of the present study was to examine whether mucinous histology (MAC and AIM) has prognostic value in stage II and III colorectal cancer patients treated with adjuvant FOLFOX. There have been controversies in prognostic impact of MAC, and some studies showed poorer prognostic role of MAC compared with NMA (Green et al, 1993; Kanemitsu et al, 2003; Negri et al, 2005; Catalano et al, 2009), whereas others did not (Farhat et al, 2008; Catalano et al, 2012; Langner et al, 2012). Most of the previous studies focused only on MAC but not on AIM. Moreover, only limited proportion of patients had been treated with adjuvant FOLFOX, which is the current standard of care in stage III disease. Using a homogeneous cohort of patients treated with adjuvant FOLFOX, we found that MAC was independently associated with a higher risk of recurrence. In contrast, AIM showed similar treatment outcome compared with NMA.

Mucinous adenocarcinoma having poor treatment outcome is in line with previous studies performed with stage IV patients receiving palliative chemotherapy (Negri et al, 2005; Catalano et al, 2009). A recent study including stage II and III colon cancer showed no prognostic role of mucinous histology (Catalano et al, 2012). However, only $16 \%$ of patients received oxaliplatin-based adjuvant chemotherapy (Catalano et al, 2012). In contrast, all patients received at least six cycles of adjuvant FOLFOX chemotherapy in the present study. As a result, $88.8 \%$ of patients had completed 12 cycles of chemotherapy, and this maybe one explanation for the relatively high 3-year DFS in this study.

Mucins are high-molecular-weight heavily glycosylated proteins that may function as chemical barriers. Over 20 MUC genes are known, which are classified into secreted or transmembrane MUCs

Table 2. Pattern of recurrence

$\boldsymbol{P}$-values

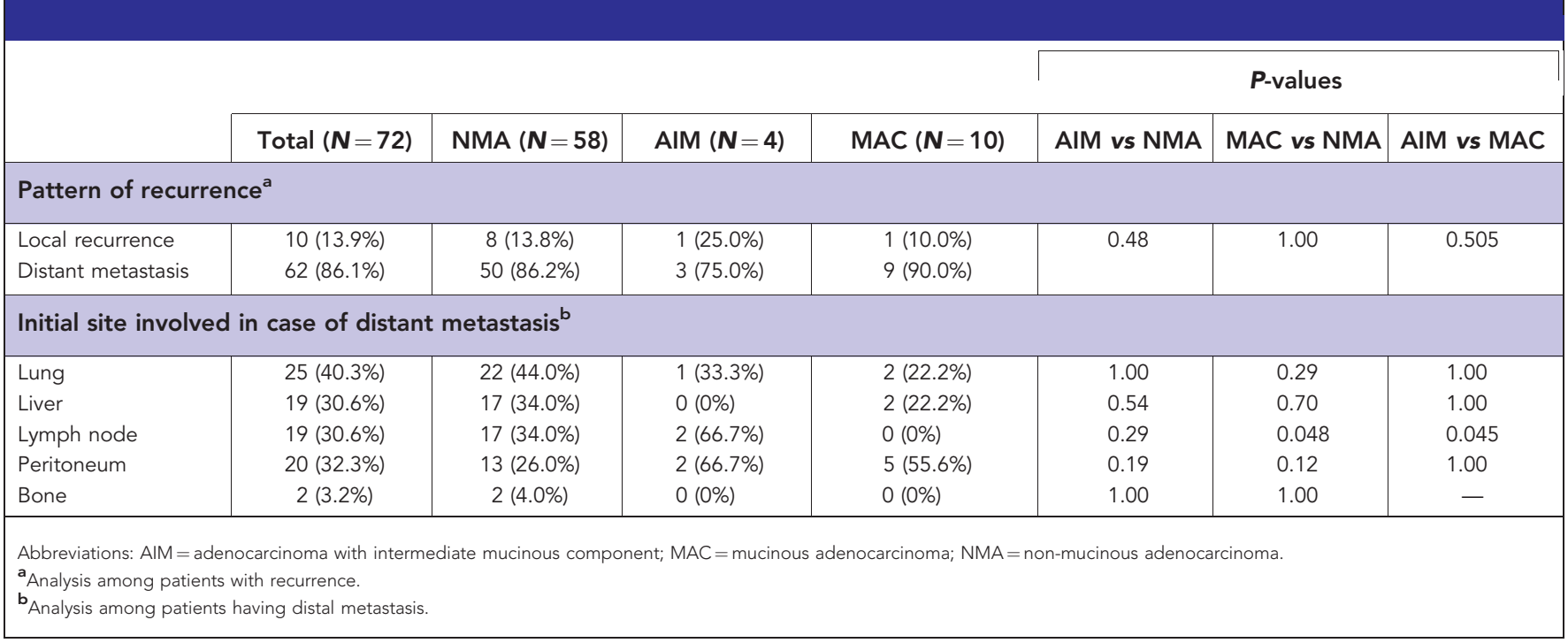




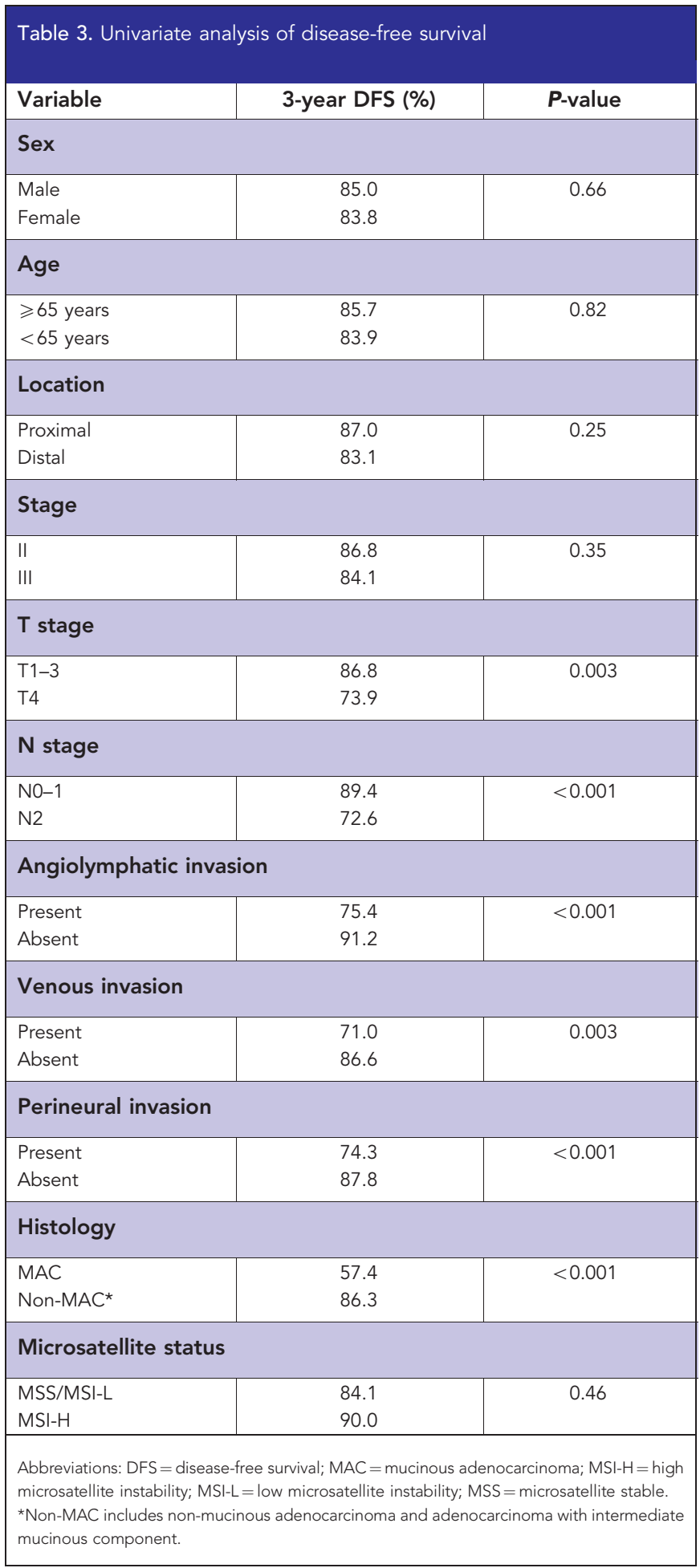

(Senapati et al, 2010). It has been shown that loss of MUC expression is an early event in colorectal carcinogenesis in a recent study (Grivennikov et al, 2012). In contrast, a number of secreted MUCs, such as MUC2, have been shown to be preserved in MAC compared with NMA (Byrd and Bresalier, 2004). Taken together, these data suggest that MAC and NMA have different mechanism of carcinogenesis. Distinct expression pattern of MUCs and higher levels of thymidylate synthase and glutathione S-transferase pi (GSTP1) in MAC maybe associated with resistance to FOLFOX (Byrd and Bresalier, 2004; Leteurtre et al, 2004; Glasgow et al, 2005). In the present study, majority of biopsy specimen from distant metastasis retained MUC production, which provides
Table 4. Multivariate analysis of disease-free survival

\begin{tabular}{|c|c|c|}
\hline & Adjusted HR $(95 \% \mathrm{Cl})$ & $\boldsymbol{P}$-value \\
\hline \multicolumn{3}{|l|}{ Histology } \\
\hline $\begin{array}{l}\text { MAC } \\
\text { Non-MAC }\end{array}$ & $\begin{array}{c}7.96(3.76-16.8) \\
1\end{array}$ & $<0.001$ \\
\hline \multicolumn{3}{|l|}{ T stage } \\
\hline $\begin{array}{l}\text { T4 } \\
\text { T1-3 }\end{array}$ & $\begin{array}{c}1.94(1.13-3.34) \\
1\end{array}$ & 0.017 \\
\hline \multicolumn{3}{|l|}{$\mathrm{N}$ stage } \\
\hline $\begin{array}{l}\text { N2 } \\
\text { N0-1 }\end{array}$ & $\begin{array}{c}2.39(1.48-3.85) \\
1\end{array}$ & $<0.001$ \\
\hline \multicolumn{3}{|c|}{ Angiolymphatic invasion } \\
\hline $\begin{array}{l}\text { Present } \\
\text { Absent }\end{array}$ & $\begin{array}{c}2.83(1.64-4.87) \\
1\end{array}$ & $<0.001$ \\
\hline \multicolumn{3}{|c|}{ Perineural invasion } \\
\hline $\begin{array}{l}\text { Present } \\
\text { Absent } \\
\end{array}$ & $\begin{array}{c}2.27(1.36-3.79) \\
1 \\
\end{array}$ & 0.002 \\
\hline \multicolumn{3}{|c|}{$\begin{array}{l}\text { Abbreviations: } \mathrm{Cl}=\text { confidence interval; } \mathrm{HR}=\text { hazard ratio; } \mathrm{MAC}=\text { mucinous adenocarci- } \\
\text { noma. } \\
{ }^{\mathrm{a}} \text { Non-MAC includes non-mucinous adenocarcinoma and adenocarcinoma with intermedi- } \\
\text { ate mucinous component. }\end{array}$} \\
\hline
\end{tabular}

evidence that MUC-producing cells are resistant to adjuvant chemotherapy and responsible for the recurrence. However, it is based on a limited number of patients and should be investigated in a larger series of paired tissues from primary and metastatic tumour. The exact mechanism of poor prognosis of MAC should be elucidated in future studies to improve treatment outcome of these patients with MAC. In the meantime, patients with MAC may benefit from a more stringent follow-up. In addition, future studies analysing the role of mucinous histology as a prognostic marker in non-high-risk stage II CRC may help identify patients that may potentially benefit from adjuvant chemotherapy.

Mucinous adenocarcinoma and MSI show geographical variation in terms of its frequencies. The reported frequencies of MAC are $3-12 \%$ in Asian studies compared with $10-39 \%$ in Western studies (Wu et al, 1996; Kanemitsu et al, 2003; Du et al, 2004; Papadopoulos et al, 2004; Kang et al, 2005; Lee et al, 2007; Leopoldo et al, 2008; Xie et al, 2009). Microsatellite instability is also more frequently found in Western patients. In stage III colorectal cancer, $11-21 \%$ show MSI in Western studies, whereas $5-8 \%$ have MSI in Asian studies (Watanabe et al, 2001; Ribic et al, 2003; Kim et al, 2010; Yoon et al, 2011; Zaanan et al, 2011; Hong et al, 2012). Mucinous adenocarcinoma is frequently associated with MSI (Leopoldo et al, 2008; Langner et al, 2012). In terms of prognosis, MSI is generally associated with favourable outcome in colorectal cancer (Popat et al, 2005; Sargent et al, 2010; Zaanan et al, 2011). However, we could not find significant role for MSI. This study was underpowered to detect significant difference of DFS according to MSI status, considering the low frequency of MSI-H in Korean patients $(6.8 \%$ in this study compared with 10 $20 \%$ in Western studies) and limited number of events in the entire cohort (3-year DFS of 84.9\%). Better outcome of MSI compared with MSS is also observed among patients with MAC (Kakar et al, 2004; Leopoldo et al, 2008). In the present study, MSI was more frequently found in MAC compared with NMA. Moreover, AIM showed similar frequency of MSI with MAC. However, we could not examine the prognostic value of MSI among MAC or AIM, because of the small number of such patients included. 
In addition to MSI, MAC is frequently associated with $\mathrm{CpG}$ island methylation phenotype (CIMP) and BRAF mutation (Ogino et al, 2006; Kakar et al, 2012). Among the present patient cohort, we had CIMP and BRAF mutation data available in 322 and 269 patients, respectively, which had been reported previously (Han et al, 2013). The frequency of high CIMP in AIM (25\%) was similar to MAC (35.3\%), which was significantly higher than that in NMA (4.6\%). BRAF mutation was found in $5.3 \%$ (1/19 patients) of AIM, $6.7 \%(1 / 15)$ of MAC, and $2.1 \%(5 / 235)$ of NMA. The number of BRAF mutations was too small to make statistical comparisons. Even though BRAF mutation has been associated with poor prognosis in colorectal cancer (Pai et al, 2012; Phipps et al, 2012; Safaee Ardekani et al, 2012), it cannot explain the poor prognosis of MAC in the present study, considering its low frequency.

In the present patient cohort, we found that AIM has similar features with MAC in terms of tumour location, angiolymphatic invasion, MSI status, CIMP status, and BRAF mutation. In contrast, AIM showed differences compared with MAC in regard to patient age, sex, and $\mathrm{T}$ stage. Most importantly, the prognosis of AIM was significantly better than MAC but comparable to NMA. Although MAC had higher percentage of T4 stage, MAC was independently associated with poor prognosis in the multivariate analysis in which T4 stage was also included as a covariate. Although we could not find differences in the molecular markers tested between AIM and MAC, it is highly likely that AIM and MAC are distinct disease entities, considering the differences in prognosis and clinicopathological characteristics. Only few prior studies have focused on comparing AIM and MAC (Ogino et al, 2006; Langner et al, 2012). Differences were observed in frequencies of MGMT loss, p16 loss, and KRAS mutation according to the degree of mucinous component (Ogino et al, 2006). However, we could not explain the poor DFS of MAC compared with AIM and NMA in the present study with those differences. Genetic or epigenetic mechanism leading to the two mucinous phenotypes, AIM and MAC, and poor prognosis of MAC should be investigated in future studies.

The major limitation of this study is that only patients treated with adjuvant FOLFOX are included. Therefore, we cannot answer whether the higher recurrence of MAC is due to its innate aggressive biology or its resistance to adjuvant chemotherapy. Nevertheless, this is the first study to evaluate the prognostic implication of mucinous histology in colorectal cancer patients treated with adjuvant FOLFOX. The study cohort was relatively homogeneous in terms of stage (only including high-risk stage II and stage III) and treatment (surgery and single chemotherapy regimen at a high-volume single institution). Our findings need further validation in an independent cohort. Another limitation is the relatively short duration of follow-up (median 38 months). We could not evaluate the impact of mucinous histology on overall survival (OS) because only limited number of events (15 deaths) was recorded. However, the median follow-up duration had passed 3 years, DFS at which point has been shown to have good correlation with 5-year OS in colon cancer (Sargent et al, 2005). Further analysis including OS will be performed after longer follow-up in the future.

In conclusion, AIM and MAC have distinct clinicopathological features compared with NMA. Only MAC, but not AIM, has an adverse prognostic impact on stage II or III colorectal cancer treated with adjuvant FOLFOX compared with NMA.

\section{ACKNOWLEDGEMENTS}

This work was supported by a grant from the Korean Healthcare Technology R\&D project, Ministry for Health, Welfare and Family Affairs, Republic of Korea (A091081).

\section{CONFLICT OF INTEREST}

The authors declared no conflict of interest.

\section{REFERENCES}

Andre T, Boni C, Navarro M, Tabernero J, Hickish T, Topham C, Bonetti A, Clingan P, Bridgewater J, Rivera F, de Gramont A (2009) Improved overall survival with oxaliplatin, fluorouracil, and leucovorin as adjuvant treatment in stage II or III colon cancer in the MOSAIC trial. J Clin Oncol 27: 3109-3116.

Bosman FT (2010) WHO classification of tumours of the digestive system. 4th edn. IARC: Lyon.

Byrd JC, Bresalier RS (2004) Mucins and mucin binding proteins in colorectal cancer. Cancer Metastasis Rev 23: 77-99.

Catalano V, Loupakis F, Graziano F, Bisonni R, Torresi U, Vincenzi B, Mari D, Giordani P, Alessandroni P, Salvatore L, Fornaro L, Santini D, Baldelli AM, Rossi D, Giustini L, Silva RR, Falcone A, D’Emidio S, Rocchi M, Luzi Fedeli S (2012) Prognosis of mucinous histology for patients with radically resected stage II and III colon cancer. Ann Oncol 23: 135-141.

Catalano V, Loupakis F, Graziano F, Torresi U, Bisonni R, Mari D, Fornaro L, Baldelli AM, Giordani P, Rossi D, Alessandroni P, Giustini L, Silva RR, Falcone A, D’Emidio S, Fedeli SL (2009) Mucinous histology predicts for poor response rate and overall survival of patients with colorectal cancer and treated with first-line oxaliplatin- and/or irinotecan-based chemotherapy. Br J Cancer 100: 881-887.

Du W, Mah JT, Lee J, Sankila R, Sankaranarayanan R, Chia KS (2004) Incidence and survival of mucinous adenocarcinoma of the colorectum: a population-based study from an Asian country. Dis Colon Rectum 47: 78-85.

Farhat MH, Barada KA, Tawil AN, Itani DM, Hatoum HA, Shamseddine AI (2008) Effect of mucin production on survival in colorectal cancer: a casecontrol study. World J Gastroenterol 14: 6981-6985.

Glasgow SC, Yu J, Carvalho LP, Shannon WD, Fleshman JW, McLeod HL (2005) Unfavourable expression of pharmacologic markers in mucinous colorectal cancer. Br J Cancer 92: 259-264.

Green JB, Timmcke AE, Mitchell WT, Hicks TC, Gathright Jr. JB, Ray JE (1993) Mucinous carcinoma-just another colon cancer? Dis Colon Rectum 36: $49-54$

Grivennikov SI, Wang K, Mucida D, Stewart CA, Schnabl B, Jauch D, Taniguchi K, Yu GY, Osterreicher CH, Hung KE, Datz C, Feng Y, Fearon ER, Oukka M, Tessarollo L, Coppola V, Yarovinsky F, Cheroutre H, Eckmann L, Trinchieri G, Karin M (2012) Adenoma-linked barrier defects and microbial products drive IL-23/IL-17-mediated tumour growth. Nature 491: 254-258.

Han SW, Lee HJ, Bae JM, Cho NY, Lee KH, Kim TY, Oh DY, Im SA, Bang YJ, Jeong SY, Park KJ, Park JG, Kang GH (2013) Methylation and microsatellite status and recurrence following adjuvant FOLFOX in colorectal cancer. Int J Cancer 132: 2209-2216.

Hong SP, Min BS, Kim TI, Cheon JH, Kim NK, Kim H, Kim WH (2012) The differential impact of microsatellite instability as a marker of prognosis and tumour response between colon cancer and rectal cancer. Eur J Cancer 48: 1235-1243.

Kakar S, Aksoy S, Burgart LJ, Smyrk TC (2004) Mucinous carcinoma of the colon: correlation of loss of mismatch repair enzymes with clinicopathologic features and survival. Mod Pathol 17: 696-700.

Kakar S, Deng G, Smyrk TC, Cun L, Sahai V, Kim YS (2012) Loss of heterozygosity, aberrant methylation, BRAF mutation and KRAS mutation in colorectal signet ring cell carcinoma. Mod Pathol 25: 1040-1047.

Kanemitsu Y, Kato T, Hirai T, Yasui K, Morimoto T, Shimizu Y, Kodera Y, Yamamura Y (2003) Survival after curative resection for mucinous adenocarcinoma of the colorectum. Dis Colon Rectum 46: 160-167.

Kang H, O'Connell JB, Maggard MA, Sack J, Ko CY (2005) A 10-year outcomes evaluation of mucinous and signet-ring cell carcinoma of the colon and rectum. Dis Colon Rectum 48: 1161-1168.

Kim ST, Lee J, Park SH, Park JO, Lim HY, Kang WK, Kim JY, Kim YH, Chang DK, Rhee PL, Kim DS, Yun H, Cho YB, Kim HC, Yun SH, Lee WY, Chun HK, Park YS (2010) Clinical impact of microsatellite instability in colon cancer following adjuvant FOLFOX therapy. Cancer Chemother Pharmacol 66: 659-667. 
Langner C, Harbaum L, Pollheimer MJ, Kornprat P, Lindtner RA, Schlemmer A, Vieth M, Rehak P (2012) Mucinous differentiation in colorectal cancer-indicator of poor prognosis? Histopathology 60: 1060-1072.

Lee WS, Chun HK, Lee WY, Yun SH, Cho YB, Yun HR, Park SH, Song SY (2007) Treatment outcomes in patients with signet ring cell carcinoma of the colorectum. Am J Surg 194: 294-298.

Leopoldo S, Lorena B, Cinzia A, Gabriella DC, Angela Luciana B, Renato C, Antonio M, Carlo S, Cristina P, Stefano C, Maurizio T, Luigi R, Cesare B (2008) Two subtypes of mucinous adenocarcinoma of the colorectum: clinicopathological and genetic features. Ann Surg Oncol 15: 1429-1439.

Leteurtre E, Gouyer V, Rousseau K, Moreau O, Barbat A, Swallow D, Huet G, Lesuffleur T (2004) Differential mucin expression in colon carcinoma HT-29 clones with variable resistance to 5-fluorouracil and methotrexate. Biol Cell 96: 145-151.

Negri FV, Wotherspoon A, Cunningham D, Norman AR, Chong G, Ross PJ (2005) Mucinous histology predicts for reduced fluorouracil responsiveness and survival in advanced colorectal cancer. Ann Oncol 16: $1305-1310$.

Ogino S, Brahmandam M, Cantor M, Namgyal C, Kawasaki T, Kirkner G, Meyerhardt JA, Loda M, Fuchs CS (2006) Distinct molecular features of colorectal carcinoma with signet ring cell component and colorectal carcinoma with mucinous component. Mod Pathol 19: 59-68.

Pai RK, Jayachandran P, Koong AC, Chang DT, Kwok S, Ma L, Arber DA, Balise RR, Tubbs RR, Shadrach B (2012) BRAF-mutated, microsatellitestable adenocarcinoma of the proximal colon: an aggressive adenocarcinoma with poor survival, mucinous differentiation, and adverse morphologic features. Am J Surg Pathol 36: 744-752.

Papadopoulos VN, Michalopoulos A, Netta S, Basdanis G, Paramythiotis D, Zatagias A, Berovalis P, Harlaftis N (2004) Prognostic significance of mucinous component in colorectal carcinoma. Tech Coloproctol $\mathbf{8}$ (Suppl 1): s123-s125.

Phipps AI, Buchanan DD, Makar KW, Burnett-Hartman AN, Coghill AE, Passarelli MN, Baron JA, Ahnen DJ, Win AK, Potter JD, Newcomb PA (2012) BRAF mutation status and survival after colorectal cancer diagnosis according to patient and tumor characteristics. Cancer Epidemiol Biomarkers Prev 21: 1792-1798.

Popat S, Hubner R, Houlston RS (2005) Systematic review of microsatellite instability and colorectal cancer prognosis. J Clin Oncol 23: 609-618.

Ribic CM, Sargent DJ, Moore MJ, Thibodeau SN, French AJ, Goldberg RM, Hamilton SR, Laurent-Puig P, Gryfe R, Shepherd LE, Tu D, Redston M, Gallinger S (2003) Tumor microsatellite-instability status as a predictor of benefit from fluorouracil-based adjuvant chemotherapy for colon cancer. N Engl J Med 349: 247-257.

Safaee Ardekani G, Jafarnejad SM, Tan L, Saeedi A, Li G (2012) The prognostic value of braf mutation in colorectal cancer and melanoma: a systematic review and meta-analysis. PLoS One 7: e47054.
Sargent DJ, Marsoni S, Monges G, Thibodeau SN, Labianca R, Hamilton SR, French AJ, Kabat B, Foster NR, Torri V, Ribic C, Grothey A, Moore M, Zaniboni A, Seitz JF, Sinicrope F, Gallinger S (2010) Defective mismatch repair as a predictive marker for lack of efficacy of fluorouracil-based adjuvant therapy in colon cancer. J Clin Oncol 28: 3219-3226.

Sargent DJ, Wieand HS, Haller DG, Gray R, Benedetti JK, Buyse M, Labianca R, Seitz JF, O'Callaghan CJ, Francini G, Grothey A, O'Connell M, Catalano PJ, Blanke CD, Kerr D, Green E, Wolmark N, Andre T, Goldberg RM, De Gramont A (2005) Disease-free survival versus overall survival as a primary end point for adjuvant colon cancer studies: individual patient data from 20,898 patients on 18 randomized trials. J Clin Oncol 23: 8664-8670.

Senapati S, Das S, Batra SK (2010) Mucin-interacting proteins: from function to therapeutics. Trends Biochem Sci 35: 236-245.

Song GA, Deng G, Bell I, Kakar S, Sleisenger MH, Kim YS (2005) Mucinous carcinomas of the colorectum have distinct molecular genetic characteristics. Int J Oncol 26: 745-750.

Verhulst J, Ferdinande L, Demetter P, Ceelen W (2012) Mucinous subtype as prognostic factor in colorectal cancer: a systematic review and metaanalysis. J Clin Pathol 65: 381-388.

Watanabe T, Wu TT, Catalano PJ, Ueki T, Satriano R, Haller DG, Benson 3rd AB, Hamilton SR (2001) Molecular predictors of survival after adjuvant chemotherapy for colon cancer. N Engl J Med 344: 1196-1206.

Wu CS, Tung SY, Chen PC, Kuo YC (1996) Clinicopathological study of colorectal mucinous carcinoma in Taiwan: a multivariate analysis. J Gastroenterol Hepatol 11: 77-81.

Xie L, Villeneuve PJ, Shaw A (2009) Survival of patients diagnosed with either colorectal mucinous or non-mucinous adenocarcinoma: a populationbased study in Canada. Int J Oncol 34: 1109-1115.

Yoon YS, Yu CS, Kim TW, Kim JH, Jang SJ, Cho DH, Roh SA, Kim JC (2011) Mismatch repair status in sporadic colorectal cancer: immunohistochemistry and microsatellite instability analyses. J Gastroenterol Hepatol 26: 1733-1739.

Younes M, Katikaneni PR, Lechago J (1993) The value of the preoperative mucosal biopsy in the diagnosis of colorectal mucinous adenocarcinoma. Cancer 72: 3588-3592.

Zaanan A, Flejou JF, Emile JF, Des GG, Cuilliere-Dartigues P, Malka D, Lecaille C, Validire P, Louvet C, Rougier P, de Gramont A, Bonnetain F, Praz F, Taieb J (2011) Defective mismatch repair status as a prognostic biomarker of disease-free survival in stage III colon cancer patients treated with adjuvant FOLFOX chemotherapy. Clin Cancer Res 17: 7470-7478.

This work is published under the standard license to publish agreement. After 12 months the work will become freely available and the license terms will switch to a Creative Commons AttributionNonCommercial-Share Alike 3.0 Unported License. 